\title{
DIAGNOSA AWAL PENYAKIT FILARIASIS PADA MANUSIA MENGGUNAKAN SISTEM PAKAR DENGAN PEMROGRAMAN VB.
}

\author{
Febby Kesumaningtyas ${ }^{1}$ \\ ${ }^{1}$ Program Studi Manajemen Informatika \\ Akademi Manajemen Informatika \& Komputer ( AMIK ) Boekittinggi \\ Email : febbykesumaningtyas25@gmail.com
}

\begin{abstract}
Abstrak: Seiring dengan berkembangnya teknologi, maka peran dari teknologi informasi semakin berguna untuk berkembang di berbagai bidang termasuk pada bidang kesehatan. Salah satunya yaitu sistem yang digunakan untuk membantu mendiagnosa penyakit filariasis, tugas akhir ini bertujuan untuk membuat aplikasi sistem pakar penyakit filariasis. Dalam penelitian ini metode yang digunakan untuk membuat sistem pakar penyakit filariasis yaitu menggunakan metode forward chaining. Pada metode forward chaining, proses pencarian data dimulai dari premis menuju kesimpulan akhir. Metode ini juga disebut data driven yaitu pencarian dikendalikan oleh data yang diberikan. Hasil akhir yang diperoleh dari penelitian ini adalah sebuah Aplikasi sistem pakar diagnosis penyakit filariasis dengan metode forward chaining, dimana user atau pengguna memasukkan data gejala yang dirasakan sesuai yang terdapat pada pilihan, lalu hasil yang diperoleh berupa gejala, kesimpulan penyakit, serta solusi pengobatan.
\end{abstract}

Kata kunci : gejala, diagnosis, forward chaining, penyakit ginjal, sistem pakar

Abstract: As the technology advances, the role of information technology even more useful for developing in various fields, including in the health field. One of them is a system used to help diagnose the disease filariasis, this thesis aims to make the application of expert systems filariasis. In this study, the method used to make the expert system filariasis is using forward chaining method. In forward chaining method, the data search process starts from the premise to the final conclusion. This method is also called data driven search is controlled by the data provided. The final results obtained from this study is an application of expert system diagnosis of filariasis with forward chaining method, where the user or users enter data on the perceived symptoms correspond contained in option, and the results obtained in the form of symptoms, the conclusions of disease, and treatment solutions.

Keywords: symptoms, diagnosis, forward chaining, kidney disease, expert systems 


\section{PENDAHULUAN}

Sistem pakar pada umumnya merupakan sistem yang berusaha mengangkat pengetahuan manusia ke komputer, agar komputer menyelesaikan masalah seperti yang biasa dilakukan oleh para ahli, atau dengan kata lain sistem pakar adalah sistem yang di desain dan di implementasikan dengan bantuan bahasa pemograman tertentu untuk dapat menyelesaikan maslah seperti yang dilakukan oleh para ahli. Selain itu, sistem pakar juga dapat memberikan hasil yang lebih konsisten dari pada pakar. Sistem pakar dapat melakukan pengambilan kesimpulan dalam waktu yang konsisten. Bahkan dalam beberapa kasus dapat menghasilkan kesimpulan lebih cepat dari pakar.

penulis bermaksud untuk merancang suatu program aplikasi sistem pakar yang mampu memberikan diagnosis yang akurat akan kemungkinan seorang manusia menderita penyakit beserta cara pengobatannya. Dimana salah satu nama penyakit yang diderita manusia itu adalah filariasis, filariasis adalah penyakit menular menahun yang disebabkan oleh Cacing Filaria yang ditularkan melalui berbagai jenis nyamuk. Penyakit filariasis ini sudah tersebar luas di pedesaan dan perkotaan, terutama di pedesaan dan tentunya penyakit ini menurunkan kualitas sumber daya manusia.

\section{TEMPAT PENELITIAN}

Penelitian dilakukan di Puskesmas Sungai Pua dan Dinas Kesehatan Lubuk Basung Kabupaten Agam. Dalam penelitian ini metode yang digunakan yaitu metode pengumpulan data berupa jenis data dan sumber data tersebut.

\section{PEMBAHASAN}

\section{Relasi Antar Tabel}

Relasi antar tabel adalah hubungan antara tabel yang mempresentasikan hubungan antar objek di dunia nyata.Relasi merupakan hubungan yang terjadi pada suatu tabel.

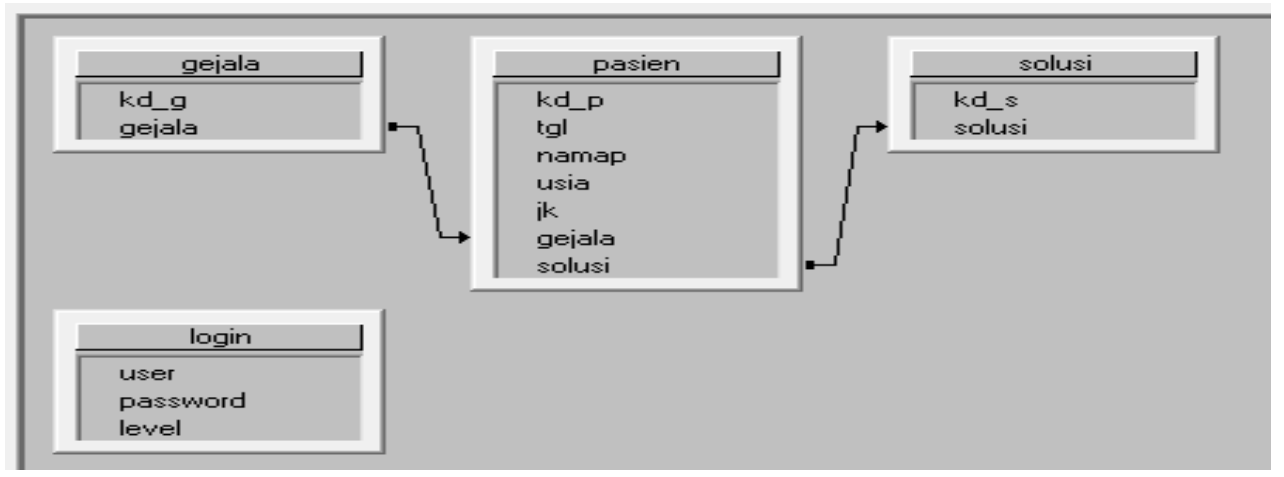

Gambar 1. Relasi Antar Tabel

Desain Input

1. Menu Utama 


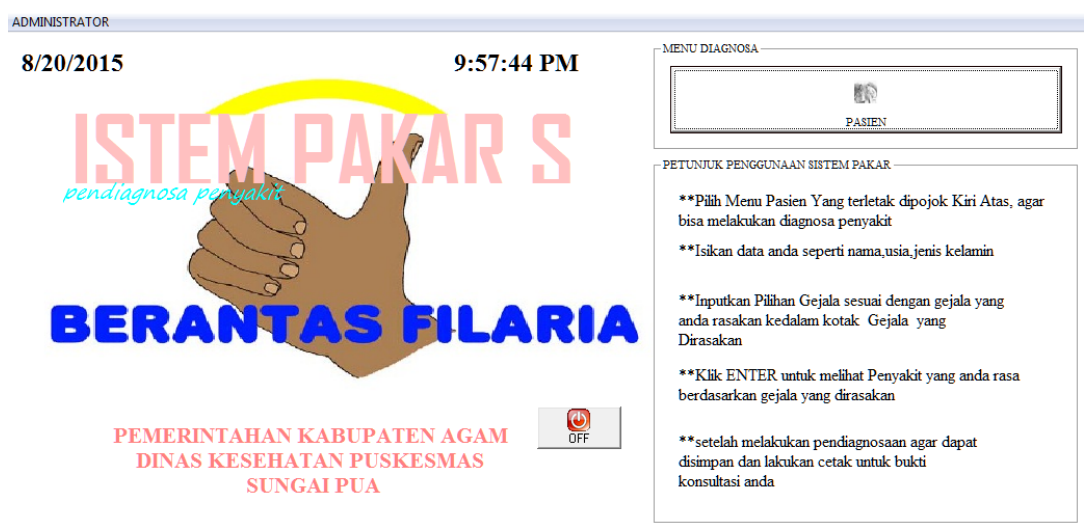

Gambar 2. Form Menu Utama

2. Tampilan Pengisian Gejala Pasien

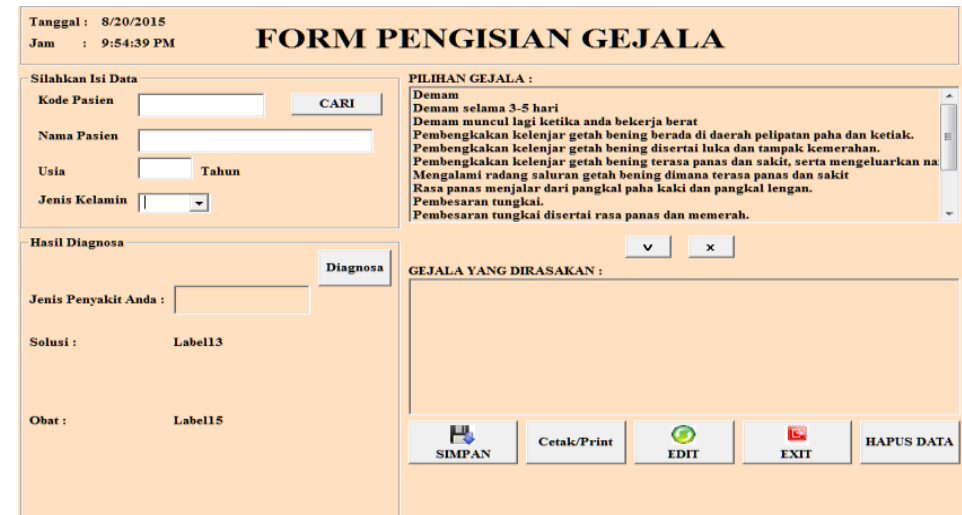

Gambar 3. Form Pengisian Gejala Pasien

\section{Tampilan Hasil Diagnosa Pasien}

HASIL DLAGNOSA ANDA

MASUKKAN KODE ANDA

I

(3)

Gambar 4. Form Hasil Diagnosa Pasien

\section{Tampilan Pilihan Menu Administrator}

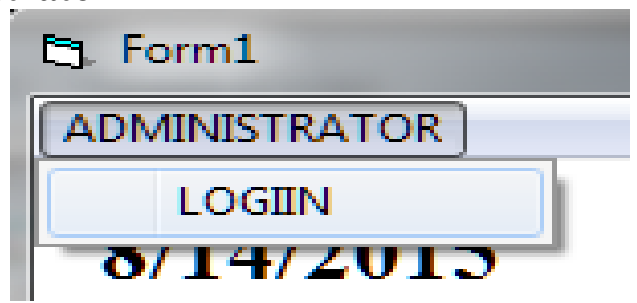

Gambar 5. Form Menu Administrator 


\section{Tampilan Login Administrator :}

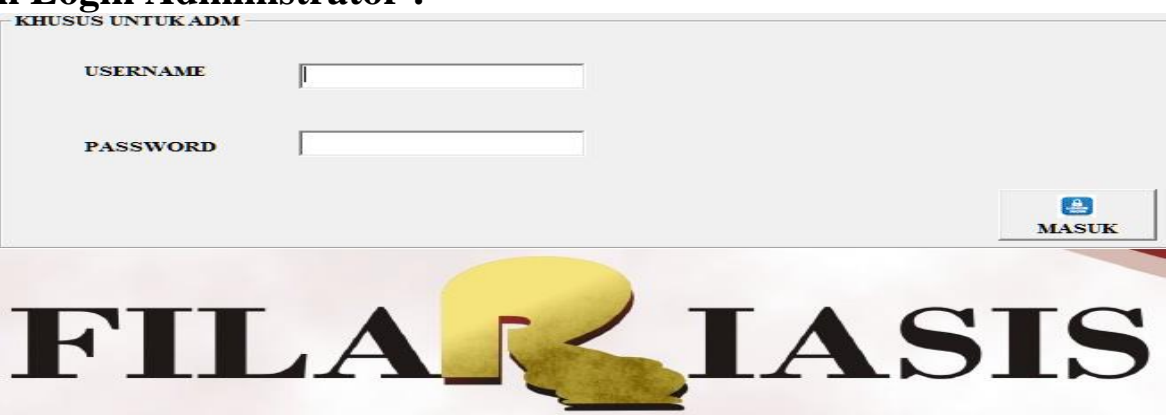

Gambar 6. Form Login Administrator

\section{Tampilan Menu Pakar}

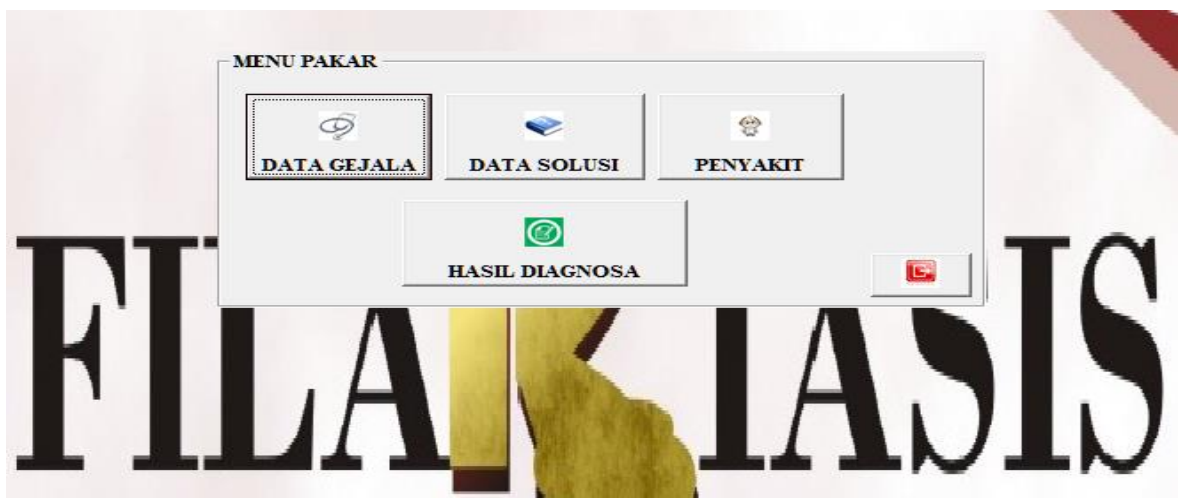

Gambar 7. Form Menu Pakar

7. Tampilan Data Gejala

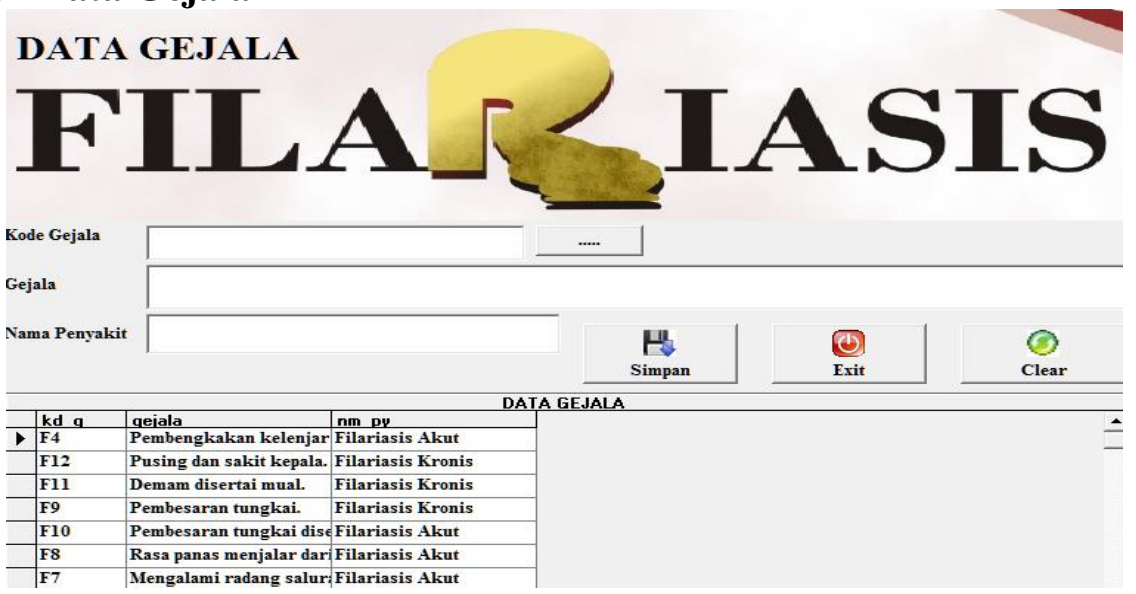

Gambar 8. Form Data Gejala

\section{Tampilan Data Solusi}




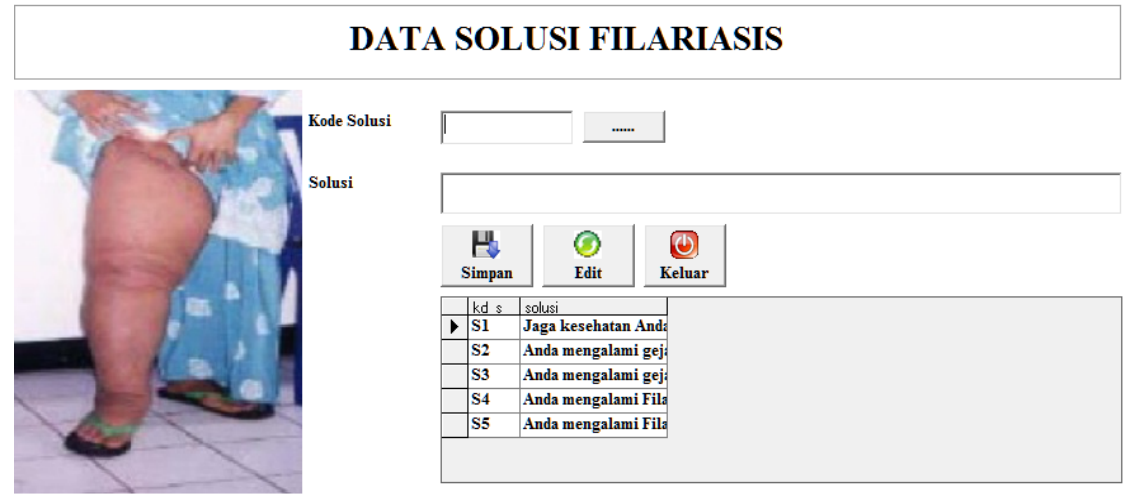

Gambar 9. Form Data Solusi

\section{Tampilan Data Penyakit}

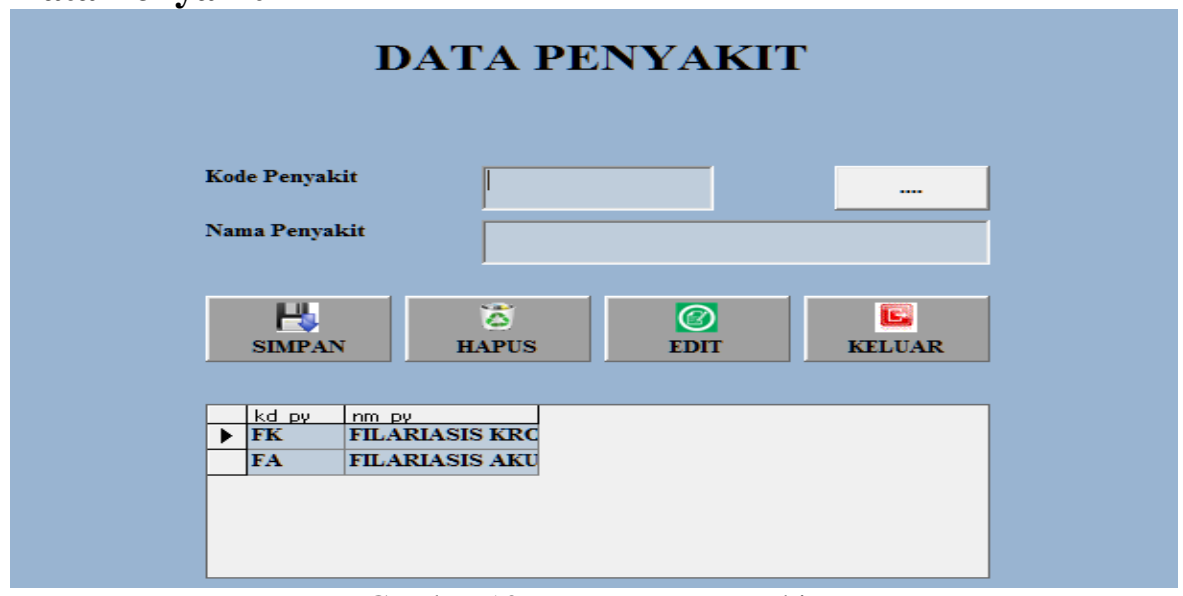

Gambar 10. Form Data Penyakit

10. Tampilan Hasil Diagnosa

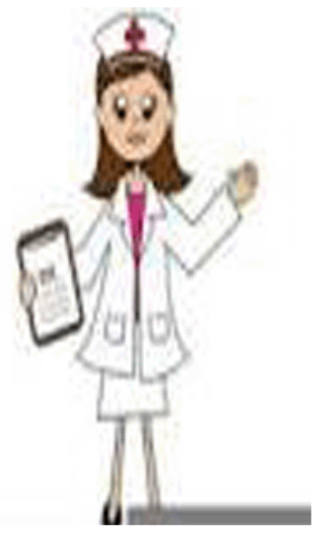

LAPORAN HASIL

diagnosa penyakit

Cetak Laporan Berdasarkan

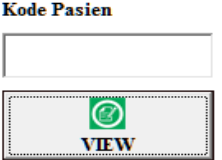

Data Keseluruhan

(2)

VIEW

Gambar 11. Form Hasil Diagnosa

\section{Desain Output}

1. Desain Laporan Per Kode Pasien 


\section{PEMERINTAH KABUPATEN AGAM DINAS KESEHATAN PUSKESMAS SUNGAI PUA}

LAPORAN HASIL DIAGNOSA FILARIASIS

\begin{tabular}{|c|c|c|c|c|c|c|c|c|}
\hline $\begin{array}{c}\text { No } \\
(\mathrm{x})\end{array}$ & $\begin{array}{c}\text { Kode } \\
\text { Pasien } \\
\text { varchar } \\
(5)\end{array}$ & $\begin{array}{c}\text { Nama } \\
\text { Pasien } \\
\text { varchar } \\
(20)\end{array}$ & $\begin{array}{c}\text { Tgl } \\
\text { date } \\
(\mathrm{x})\end{array}$ & $\begin{array}{c}\text { Usia } \\
\text { int } \\
(10)\end{array}$ & $\begin{array}{c}\text { JK } \\
\text { varchar } \\
(5)\end{array}$ & $\begin{array}{c}\text { Penyakit } \\
\text { varchar } \\
(20)\end{array}$ & $\begin{array}{c}\text { Solusi } \\
\text { varchar } \\
(900)\end{array}$ & $\begin{array}{c}\text { Obat } \\
\text { varchar } \\
(1000)\end{array}$ \\
\hline 7 & $\longrightarrow$ & $\longrightarrow$ & & & & \\
\hline
\end{tabular}

Sungai Pua, MM-DD-YYYY

Dokter Puskesmas Sungai Pua,

Dr. M. Ghazali S.

Gambar 12. Desain Laporan Per Kode Pasien

\section{Laporan Hasil Diagnosa Per Kode Pasien}

\begin{tabular}{|c|c|c|c|c|c|c|c|c|}
\hline No. & KD P & $\begin{array}{l}\text { NAMA } \\
\text { PA SIEN }\end{array}$ & T GL & U SIA & JK & PENYAKIT & SOL USI & OBAT \\
\hline 1 & 001 & IGA & $8 / 15 / 2$ & 20 & P & Filariasis Kronis & $\begin{array}{l}\text { Anda mengalami Filariasis } \\
\text { Kronis, segera periksakan } \\
\text { ke dokter spesialis penyakit } \\
\text { dalam untuk mendapatkan } \\
\text { penanganan lebih lanjut. }\end{array}$ & $\begin{array}{l}\text { Diethylcarbamazine dan } \\
\text { Albendazol aturan dosis } \\
\text { yang dianjurkan untuk } 6 \\
\text { mg/kg berat badan per } \\
\text { hari, selama } 12 \text { hari } \\
\text { diminum pada malam } \\
\text { hari sesudah makan } \\
\text { malam sebelum tidur, } \\
\text { dalam sehari } 3 \text { kali }\end{array}$ \\
\hline
\end{tabular}

Sung ai Pua, 8/21/2015

Dokter Puskesmas Sungai Pua

Gambar 13. Laporan Hasil Diagnosa Per Kode Pasien

\section{Desain Laporan Secara Menyeluruh}




\section{PEMERINTAH KABUPATEN AGAM DINAS KESEHATAN PUSKESMAS SUNGAI PUA}

LAPORAN HASIL DIAGNOSA FILARIASIS

\begin{tabular}{|c|c|c|c|c|c|c|c|c|}
\hline $\begin{array}{c}\text { No } \\
(\mathrm{x})\end{array}$ & $\begin{array}{c}\text { Kode } \\
\text { Pasien } \\
\text { varchar } \\
(5)\end{array}$ & $\begin{array}{c}\text { Nama } \\
\text { Pasien } \\
\text { varchar } \\
(20)\end{array}$ & $\begin{array}{c}\text { Tgl } \\
\text { date } \\
(\mathrm{x})\end{array}$ & $\begin{array}{c}\text { Usia } \\
\text { int } \\
(10)\end{array}$ & $\begin{array}{c}\text { JK } \\
\text { varchar } \\
(5)\end{array}$ & $\begin{array}{c}\text { Penyakit } \\
\text { varchar } \\
(20)\end{array}$ & $\begin{array}{c}\text { Solusi } \\
\text { varchar } \\
(900)\end{array}$ & $\begin{array}{c}\text { Obat } \\
\text { varcha } \\
\mathrm{r} \\
(1000)\end{array}$ \\
\hline 7 & $\longrightarrow$ & $\longrightarrow$ & $\longrightarrow$ & & \\
\hline & & & & & &
\end{tabular}

Sungai Pua, MM-DD-YYYY

Dokter Puskesmas Sungai Pua,

\section{Dr. M. Ghazali S.}

Gambar 14. Laporan Hasil Diagnosa Secara Menyeluruh

\section{Laporan Hasil Diagnosa Secara Menyeluruh}

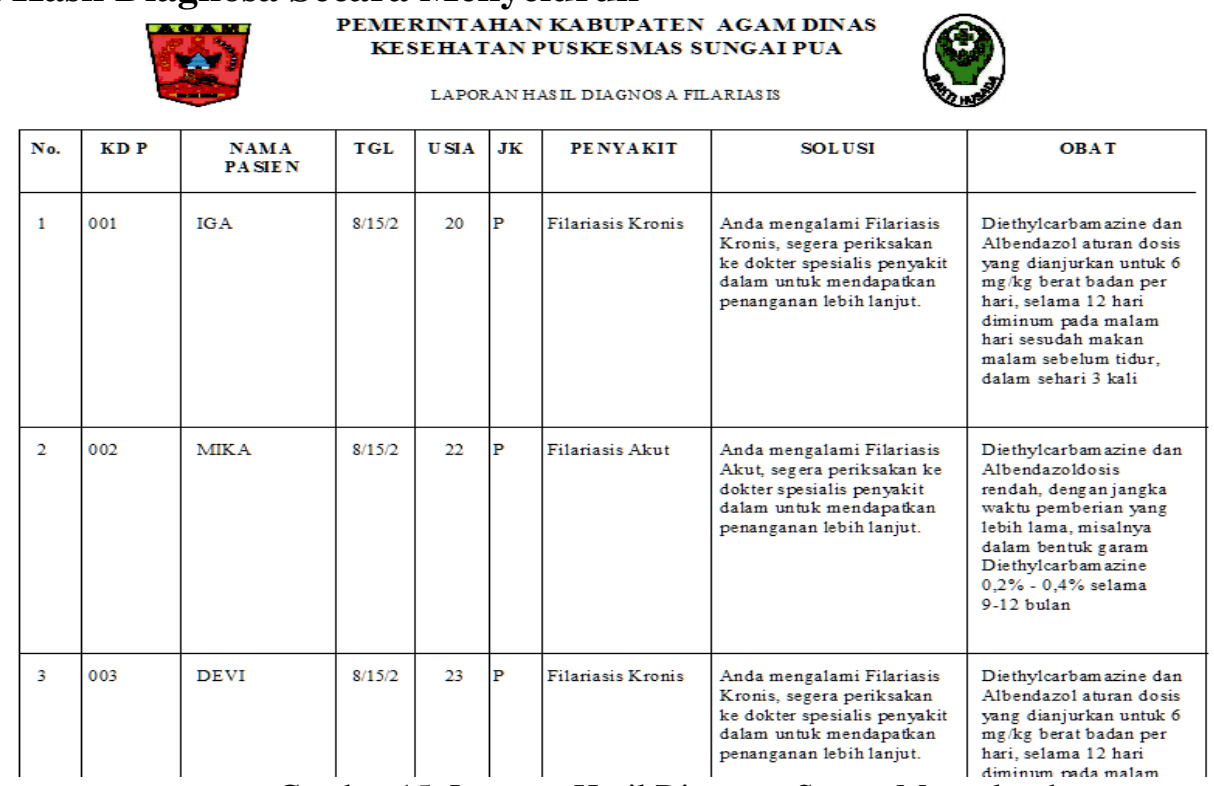

Gambar 15. Laporan Hasil Diagnosa Secara Menyeluruh 


\section{KESIMPULAN}

a. Dalam penelitian ini dibangun sebuah aplikasi sistem pakar untuk mendiagnosa penyakit filariasis pada manusia yang dapat membantu petugas puskesmas untuk membuat sebuah hasil diagnosa yanag berupa laporan berdasarkan kode pasien dan laporan secara menyeluruh dengan aplikasi sistem pakar tersebut.

b. Setelah dilakukan pembandingan antara sistem yang lama dengan sistem yang baru ke beberapa user, hasil yang diperoleh adalah aplikasi sistem pakar yang baru lebih mudah untuk digunakan baik untuk pengolahan data maupun untuk penyajian laporannya.

c. Telah berhasil sistem pakar sebagai aplikasi untuk mendiagnosa penyakit filariasis pada manusia dengan menggunakan metode forward chaining di Puskesmas Sungai Pua.

d. Sistem memberikan solusi rekomendasi mengenai penyakit filariasis kepada pengguna (user) sesuai dengan gejala yang di inputkan sebelumnya.

\section{DAFTAR PUSTAKA}

Sri Hartati dan Sari Iswanti . 2008. Sistem Pakar Dan Pengembangannya. Graha Ilmu :Yogyakarta.

Kusrini, S.kom. 2006. Sistem Pakar, Teori Dan Aplikasi. Andi: Yogyakarta.

Tim Penerbit Andi. 2003. Pengembangan Sistem Pakar Menggunakan Visual Basic. Andi : Yogyakarta.

T. Sutojo, S.si,M.kom, Edy Mulyanto, S.si,M.kom, Dr. Vincent Suhartono.2011. Kecerdasan Buatan. Andi. Yogyakarta.

Kusrini,M.kom. Aplikasi Sistem Pakar.2006. Andi, Yogyakarta.

(Yanti, EF., 2016) Listiyono, H. (2008). Merancang dan Membuat Sistem Pakar, $\operatorname{XIII}(2), 115-124$.

Yanti, EF., \& H. (2016). Penerapan Metode Forward Dan Backward Chaining Dalam Sistem Pakar Pemilihan Resep. Jurnal STMIK PalComTech, 1-13. 